\title{
Five-membered iminocyclitol $\alpha$-glucosidase inhibitors: Synthetic, biological screening and in silico studies
}

\author{
Luis R. Guerreiro ${ }^{a}$, Elisabete P. Carreiro ${ }^{a}$, Luis Fernandes ${ }^{a}$, Teresa A. F. Cardote ${ }^{b}$, Rui Moreira ${ }^{b}$, \\ Ana T. Caldeira ${ }^{a}$, Rita C. Guedes ${ }^{b}$, A. J. Burke ${ }^{a, *}$ \\ ${ }^{a}$ Departamento de Química and Centro de Química de Évora, Universidade de Évora, Rua Romão Ramalho, 59, 7000 Évora, Portugal \\ ${ }^{\mathrm{b}}$ Research Institute for Medicines and Pharmaceutical Sciences-iMed.UL, Faculty of Pharmacy, University of Lisbon, Av. Prof. Gama Pinto, 1649-003 Lisbon, Portugal
}

\section{A R T I C L E I N F O}

\section{Article history:}

Received 16 November 2012

Revised 10 January 2013

Accepted 14 January 2013

Available online 26 January 2013

\section{Keywords:}

Iminocyclitol

Small molecule inhibitor

$\alpha$-Glucosidase

Enantiopure compound

(3,4)-Dihydroxypyrrolidine

\begin{abstract}
A B S T R A C T
The design and synthesis of a small library of pyrrolidine iminocyclitol inhibitors with a structural similarity to 1,4-dideoxy-1,4-imino-D-arabitol (DAB-1) is reported. This library was specifically designed to gain a better insight into the mechanism of inhibition of glycosidases by polyhydroxylated pyrrolidines or iminocyclitols. Pyrrolidine-3,4-diol 15a and pyrrolidine-3,4-diol diacetate 15b had emerged as the most potent $\alpha$-glucosidase inhibitors in the series. Docking studies performed with an homology model of $\alpha$-glucosidase disclosed binding poses for compounds $15 \mathbf{a}, \mathbf{1 5} \mathbf{b}, \mathbf{1 6} \mathbf{a}$, and $\mathbf{1 6} \mathbf{a}^{\prime}$ occupying the same region as the $\mathrm{NH}$ group of the terminal ring of acarbose and suggest a closer and stronger binding of compound 15a and 15b with the enzyme active site residues. Our studies indicate that 2 or 5-hydroxyl substituents appear to be vital for high inhibitory activity.
\end{abstract}

๑ 2013 Elsevier Ltd. All rights reserved.

\section{Introduction}

The iminocyclitols-polyhydroxylated pyrrolidines and piperidines-are a family of important pharmacologically active compounds that are both potent glycosidase and glycosyltransferase inhibitors due to their mimicry of the transition state of the enzymatic reaction, including serendipitous electrostatic binding interactions. ${ }^{1,2}$ For this reason, they have been selected as therapeutic agents in several areas such as cancer, viral infections (particularly influenza) and diabetes, etc. For example, deoxinojirimicin (DNJ) 1 is an inhibitor of endoplasmic reticulum $\alpha$-glucosidases $\mathrm{I}^{3}$ and 1,4-dideoxy-1,4-imino-D-arabinitol (DAB-1) 2 and 2,5-dideoxy2,5-imino-D-mannitol (DMDP) $\mathbf{3}^{5}$ are powerful inhibitors of $\alpha$-glucosidases ${ }^{4}$ (Fig. 1 ). The synthesis of more potent novel analogues of these compounds is an important goal in medicinal chemistry, not only for targeting human disease, but also as tools to probe the mechanism of glucosidase function. In most cases, these molecules function as pure enantiomers.

It has been previously pointed out that structure-activity relationships for iminocyclitol glycosidase inhibitors are difficult to elucidate, making rational inhibitor design a difficult task. ${ }^{1}$ It is also known that five-membered iminocyclitols can give rise to higher inhibition than their six-membered counterparts and subtle selectivities may be observed for five- over six-membered systems, thus making logical design based upon structural analogy diffi-

\footnotetext{
* Corresponding author. Tel.: +351266745310
}

cult. ${ }^{6}$ For this reason many types of five-membered iminocyclitols have been synthesized and screened. An examination of the literature showed that a number of diverse structural types have been screened for $\alpha$-glucosidase inhibition. This includes those developed by Davis, for example, $4^{6}$ (Fig. 1 ) obtained from 3-pyrroline and tartaric acid, and showed no significant inhibition (3-13\% at the $1 \mathrm{mM}$ level). The five-membered iminocyclitol amide derivatives 5 developed by Wong's group showed inhibition with a $K_{\mathrm{i}}$ value of $53 \mathrm{nM}^{7}$ (which was better than that exhibited by the parent structure 6) and the 2-alkylated analogues of type 7 (Fig. 1) were also shown by Wong ${ }^{1 \mathrm{~b}}$ to be weak $\alpha$-glucosidase inhibitors (3-54\% inhibition at $200 \mu \mathrm{M}$ ). Davis has also shown that a library of $\mathrm{N}$-acyl(aroyl)-2-carboxyamide substituted pyrrolidine iminocyclitols of type $\mathbf{8}$, showed little or no inhibition at $100 \mu \mathrm{M} .{ }^{8}$ Wong has prepared and tested pyrrolidine iminocyclitols of type $\mathbf{9}$ with side-chains in both the 2 and the 5 positions, ${ }^{9}$ in which some were very potent inhibitors. Calveras et al. ${ }^{10}$ showed that a library of iminocyclitols of type 10 inhibited this enzyme at 1.6-4.2 $\mathrm{nM}$ level. In most cases the presence of a hydroxymethyl appendage seems to give significant inhibition, whereas when substituted by an alkyl group, as in $\mathbf{4}$ and $\mathbf{7}$ (Fig. 1), the inhibition is weaker or even absent, indicating that this substituent must be relevant to approximate the structures of the natural $\alpha$-glucosidase sugar substrate. ${ }^{6}$ This point has been echoed by Wong ${ }^{9}$ and indeed, this hypothesis has been supported somewhat by the work of both Bols ${ }^{11}$ and Lundt, ${ }^{12}$ who prepared the 2,5-non-substituted pyrrolidine iminocyclitols 11, 12 and 13, with the hydroxymethyl appendage transposed to 